\title{
Applications of Propolis in Dentistry: A Review
}

\author{
Amir Jalal Abbasi ${ }^{1}$, Farnoush Mohammadi', Mohamad Bayat ${ }^{1}$, Shimelis \\ Megersa Gema ${ }^{4}$, Hannaneh Ghadirian ${ }^{2}$, Hasti Seifi ${ }^{3}$, Hananeh Bayat ${ }^{3}$, Naghmeh \\ Bahrami $^{1 *}$
}

\footnotetext{
OPEN ACCESS

Citation: Amir Jalal Abbasi, Farnoush Mohammadi, Mohamad Bayat, Shimelis Megersa Gema, Hannaneh Ghadirian, Hasti Seifi, Hananeh Bayat and Naghmeh Bahram. Applications of Propolis in Dentistry: A review. Ethiop J Health Sci.2017;28(4):509. doi:http://dx.doi.org/10.4314/ejhs.v28i4.16 Received: February 8, 2018 Accepted: February 8, 2018

Published: July 1, 2018

Copyright: (C) 2018 Amir Jalal A., et al. This is an open access article distributed under the terms of the Creative Commons Attribution License, which permits unrestricted use, distribution, and reproduction in any medium, provided the original author and source are credited. Funding: Nil

Competing Interests: The authors declare that this manuscript was approved by all authors in its form and that no competing interest exists.

Affiliation and Correspondence: ${ }^{1}$ Craniomaxillofacial Research Center, Tehran University of Medical Sciences, Tehran, Iran; Oral and Maxillofacial Surgery Department, School of Dentistry, Tehran University of Medical Sciences, Tehran, Iran

${ }^{2}$ Dental Research Center Dentistry Research Institute, Orthodontic Department, Tehran University of Medical Sciences, Tehran, Iran

${ }^{3}$ Craniomaxillofacial Research Center, Tehran University of Medical Sciences, Tehran, Iran;

${ }^{4}$ Department of Oral and Maxillofacial surgery, Institute of health science, Jimma University, Jimma, Ethiopia

*Email: n-bahrami@sina.tums.ac.ir
}

\section{ABSTRACT}

BACKGROUND: Propolis is a resinous substance obtained from the beehives that has antioxidant, anti-bacteria, anti-virus, antifungal, anti-tumor and anti-inflammatory activity. The aim of this study was to review the studies about the role of propolis in improving dental and oral health.

METHODS: This study reviewed the published articles regarding the applications of propolis in dentistry. An electronic search of the literature was carried out in Farsi electronic databases including Google, Medlib.ir, SID, Iranmedex and Magiran as well as English electronic databases such as PubMed and ISI Web of Knowledge. These databases were searched for articles published between 1997 and October 20, 2017. Non-dental books and journals were also manually searched.

RESULTS: This study reviewed published articles on the efficacy of propolis for surgical wound healing, caries prevention, treatment of dentin hypersensitivity, treatment of aphthous ulcers and propolis as a storage medium for avulsed teeth, root canal irrigating solution and mouthwash.

CONCLUSION: The result of the reviewed article showed that propolis is effective an agent that is used for multiple purpose in oral health.

KEYWORDS: Propolis, Dentistry, Honeybee, Oral health

\section{INTRODUCTION}

Bees saliva with wax and exudates collected from botanical sources, used to seal the gaps in the hive and protect it against light, moisture, invaders and external factors. Moreover, it is used to disinfect the internal environment of the hive and adjust the internal temperature (1). Its constituents include resin and balsams (50-70\%), wax (30$50 \%$ ), pollens (5-10\%), amino acids, minerals, vitamins A, B and E, phenols and aromatic compounds. The percentage of carbohydrates varies in different types of propolis. Propolis has antioxidant activity (2), which is even more potent than the antioxidant activity of vitamin C (3). Flavonoids comprise a large part of the resinous portion of propolis and are in fact its active component. They are responsible for the majority of anti-oxidative, antibacterial, antiviral, antifungal, anti-cariogenic and anti-inflammatory properties of propolis (4). 
Its antibacterial activity is particularly effective against Gram-positive bacteria (5), such as Staphylococcus aureus (S. aureus) (3) and Gramnegative bacteria like Salmonella (6). The efficacy of propolis for inhibition of the activity of glycosyltransferase enzyme of Streptococcus circuits, Streptococcus mutans and Streptococcus sobrinus has been confirmed in vivo and in vitro (7). Propolis induces the synthesis of insoluble glycan and inhibits the activity of glycosyltransferase enzyme (8). Researchers evaluated the antibacterial activity of propolis against some anaerobic oral pathogens and confirmed that its effectiveness against Lactobacillus acidophilus, Actinomyces naeslundii, Prevotella oralis, Prevotella melaninogenica, Porphyromonas gingivalis, Fusobacterium nucleatum and Veillonella parvula, mainly due to the presence of flavonoids and aromatic compounds such as caffeic acid in its composition (9).

Kujumgiev et al. (10) assessed the antibacterial activity of propolis against $\mathrm{S}$. aureus and Escherichia coli, its antifungal efficacy against Candida albicans (C. albicans) and its antiviral effects on avian influenza virus in which reported its optimal efficacy against all. Moreover, application of propolis along with antibiotics increases their efficacy by 10 to 100 times and seems to have a synergistic effect with them.

Propolis also possesses anti-inflammatory properties via inhibiting the production of prostaglandins through inhibiting lipoxygenase enzyme. Its anti-inflammatory and analgesic properties are similar to those of aspirin but with fewer side-effects (11). It also increases the production of interferons and antibodies. At present, it is incorporated in the composition of tooth pastes (12), mouthwashes (13), lozenges, drinks, cakes, powders, gelatos, tablets and soaps (14). This study aimed to review the applications of propolis in dentistry and its role in oral health.

\section{MATERIALS AND METHODS}

Electronic search of the literature was carried out in Farsi electronic databases including Google, Medlib.ir, SID, Iranmedex and Magiran as well as English electronic databases such as PubMed and
ISI Web of Knowledge. These databases were searched for articles published between 1997 and October 20, 2017. Non-dental books and journals were also manually searched. The inclusion criteria were (I) access to full text of article, (II) articles in Farsi or English and (III) adequate sample size and correct statistical analyses. The excluded articles were: (I) systematic reviews, case reports, letter to editors and congress abstracts.

We read full text of all articles that mentioned the use of propolis in their topics or abstracts and selected those that fulfilled our inclusion criteria. Any reference that could contribute to the purpose of the systematic review was retrieved.

\section{RESULTS}

This study reviewed published articles on the efficacy of propolis for surgical wound healing, caries prevention, treatment of dentin hypersensitivity, treatment of aphthous ulcers and propolis as a storage medium for avulsed teeth, root canal irrigating solution and mouthwash.

Propolis for surgical wound healing: Carvalho and Magro (15) in their study asked patients to rinse their mouth with propolis alcoholic extract after tooth extraction to assess its efficacy for alveolar socket wound healing. The patients were recalled 7, 14, 30 and 45 days after surgery and subjected to cellular and clinical examinations. The results showed that the mouthwash enhanced wound healing and showed anti-inflammatory and analgesic properties. Exfoliative cytological assessment showed that surgical wounds was epithelized. Olczyk et al. (16) compared the efficacy of propolis and silver sulfadiazine for synthesis and accumulation of types I and III collagen and they found the superior efficacy of propolis for synthesis of types I and III collagen.

Propolis as storage medium for avulsed teeth: Time spent out of the alveolar socket and the storage mediums significantly affect the long-term prognosis of replanted avulsed teeth. Pileggi and Martin (17) used Hank's balanced salt solution (HBSS), milk, propolis and salt as storage media for avulsed teeth and reported that propolis was superior to HBSS, milk and salt since the number

DOI: http://dx.doi.org/10.4314/ejhs.v28i4.16 
of survived periodontal ligament (PDL) cells washigher in propolis.

Propolis as culture medium for PDL cells: Ozan et al. (18) stored PDL cells of extracted teeth in propolis to assess its biocompatibility. The cells had been isolated from extracted sound third molars and were cultured in Dulbecco's modified Eagle's medium (DMEM). The cells were then stored in 10 and $20 \%$ propolis solution, low fat milk, HBSS, water and milk as negative control and DMEM as positive control. The trypan blue exclusion test was used to determine the biocompatibility of PDL cells. Gopikrishna et al. (19) compared coconut water and propolis as storage media to find out which one better maintains the PDL cells viable. The teeth were kept dry for 30 minutes and were then immersed in the two storage media. The teeth were then removed and treated with grade II dispase and collagenase for 30 minutes. The viable PDL cells were then counted using a hemocytometer. The results showed that more PDL cells remained viable in coconut water.

Al-Shaher et al. (20) compared the viability of PDL and dental pulp fibroblasts exposed to propolis and calcium hydroxide powder in vitro. The dental pulp and PDL fibroblasts were isolated from extracted human third molars. The cells were exposed to various concentrations of propolis $(0-20 \mathrm{mg} / \mathrm{mL})$ and calcium hydroxide $(0-250 \mathrm{mg} / \mathrm{mL})$ then stained with Crystal Violet dye and subjected to spectrophotometry. The results showed that $75 \%$ of PDL and dental pulp fibroblasts exposed to 4 $\mathrm{mg} / \mathrm{mL}$ or lower concentrations of propolis remained viable. In contrast, $4 \mathrm{mg} / \mathrm{mL}$ calcium hydroxide was cytotoxic for cells, and less than $25 \%$ of cells exposed to this concentration survived. They concluded from their result that propolis is a suitable storage medium for extracted teeth.

Propolis as intracanal irrigating solution: Qathami and Al-Madi (21) assessed the antimicrobial efficacy of propolis, sodium hypochlorite and salt for intracanal irrigation. Microbial samples were obtained immediately after opening the canal, access cavity preparation and root canal preparation and irrigation. They evaluated the effect of propolis on the number of colony forming units. The results of this study showed that the antimicrobial activity of propolis was similar to that of sodium hypochlorite. Kandaswamy et al. (22) divided 180 extracted teeth exposed to Enterococcus faecalis for 21 days into six groups depending on type of intracanal irrigating solution going to be used (Saline, propolis, MCJ, $2 \%$ povidone iodine, $2 \%$ chlorhexidine gel and calcium hydroxide). The number of viable colonies in dentinal tubules at 200 and $400 \mu$ depth was counted after one, three and five days. The results showed that chlorhexidine gluconate $(100 \%)$ had better antimicrobial activity than $2 \%$ povidone iodine $(87 \%)$, propolis $(71 \%)$, MCJ $(69 \%)$ and calcium hydroxide $(55 \%)$. No significant difference was noted in the efficacy of propolis and MCJ at 200 or $400 \mu \mathrm{m}$ depths. The results showed that propolis and MCI were effective against E. faecalis in dentin of extracted teeth.

Propolis as intracanal medicament: Oncag et al. (23) assessed the efficacy of three intracanal medicaments and propolis against E. faecalis and reported that propolis as intracanal medicament prevented the growth and proliferation of $\mathrm{E}$. faecalis and had suitable antibacterial efficacy. Awawdeh et al. (24) compared propolis and calcium hydroxide as intracanal medicament and showed that propolis was an effective intracanal medicament and quickly eliminated $\mathrm{E}$. faecalis.

Rezende et al. (25) evaluated the antimicrobial activity of two pastes containing propolis and calcium hydroxide against polymicrobial cultures taken from the root canals of 16 necrotic primary molars. They used agar well-diffusion technique to determine the antimicrobial activity of the following pastes: $11 \%$ ethanolic extract of propolis + calcium hydroxide; and $11.0 \%$ extract of propolis without ethanol + calcium hydroxide. The results showed that antimicrobial activity of the latter paste was higher than the former paste $1(\mathrm{P}=0.053)$. However in general, both pastes showed high antimicrobial activity. They concluded that combination of propolis and calcium hydroxide is effective to control dental infections.

DOI: http://dx.doi.org/10.4314/ejhs.v28i4.16 
Comparison of propolis with other mouthwashes: Ozan et al. (26) described the efficacy of different concentrations of propolis solutions and $0.2 \%$ chlorhexidine (control group) against oral microorganisms and their effects on human gingival fibroblasts. They used propolis mouthwash in 1, 2.5, 5 and $10 \%$ concentrations. Chlorhexidine was found to be more effective against oral microorganisms. On the other hand, chlorhexidine showed more cytotoxicity against gingival fibroblasts.

Propolis is used to maintain oral health and prevent caries due to its antibiotic and anti-plaque properties. A simple mouthwash of propolis can be made by adding 10-50 drops of propolis to one glass of warm water. In contrast to commonly used mouthwashes, propolis mouthwash can be swallowed to further benefit from it (27).

Propolis for caries prevention: Hayacibara et al. (28) assessed the effect of propolis on viability of Streptococcus mutans, glucosyltransferase activity and caries extension in rats. They reported that propolis was a good cariostatic agent that inhibited the activity of this enzyme. The same finding was reported by Ikeno et al (7). Koo et al. (39) evaluated the effect of constituents of propolis on the activity of glucosyltransferase enzyme in bacteria and caries extension and found that apigenin was a strong agent for prevention of the activity of glucosyltransferase enzyme. They also showed that $t$-farnesol was an effective antibacterial agent.

\section{Propolis for treatment of dentin} hypersensitivity: Mahmoud et al. (30) evaluated the effect of propolis on dentin hypersensitivity. Using electron microscopy, they noticed that propolis obstructed the dentinal tubules. Madhavan et al. (31) compared the clinical efficacy of casein phosphopeptide amorphous calcium phosphate fluoride, sodium fluoride, propolis and distilled water (as placebo) after eight days, 60 days and three months of use. The results showed that propolis was the best material for treatment of dentin hypersensitivity. All materials were more effective than distilled water, and their difference was in their time of effect within three months.
Propolis as pulp capping agent: The outcome of treatment was similar to that of mineral trioxide aggregate and calcium hydroxide. The effectiveness of propolis was due to its resinous and adhesive properties, since it seals the dentinal tubules and has anti-inflammatory property that decreases pulpal inflammation (4,32). Another study by Sabir et al. (33) described dental pulp response of rats to direct pulp capping with propolis. The rats were divided into three groups of nine. Class 1 cavities were prepared on the occlusal surface of maxillary right first molars. Dental pulp was exposed and zinc oxide-based filler (control group), propolis flavonoids or nonflavonoids were placed in the cavities. The results revealed that dental pulp capping with propolis flavonoids in rats postponed pulpal inflammation and induced dentin regeneration.

Propolis for treatment of periodontitis: Murray et al. (33) assessed the effect of a mouthwash containing propolis, chlorhexidine and a placebo on microbial plaque formation. Chlorhexidine was found to be much more effective than others were and prevented plaque formation. Propolis mouthwash was slightly better than the negative control and this difference was not statistically significant. Difference in the results of the aforementioned two studies may be due to different methodologies. Koo et al. (34) evaluated the efficacy of a mouthwash containing RS-SNB propolis on dental plaque accumulation in three days. Plaque index and insoluble polysaccharides were assessed in supragingival plaque after three days and plaque index was found to be 0.78 in the test group and 1.41 in the placebo group. Thus, propolis mouthwash effectively decreased plaque index and insoluble polysaccharides by $61.7 \%$.

Hidaka et al. (38) evaluated the preventive effect of propolis on conversion of non-crystal calcium phosphate (which plays a role in calculus formation) to hydroxyapatite. Considering the anti-plaque and anti-inflammatory effects of propolis and its efficacy in formation of alveolar bone, it seems that propolis can be used for treatment of periodontal disease. Enhanced protein synthesis, cell mitosis, increased cell metabolism and collagen synthesis are critical for gingival structure and treatment of periodontitis.

DOI: http://dx.doi.org/10.4314/ejhs.v28i4.16 
Effect of propolis on recurrent aphthous stomatitis: Samet et al. (37) evaluated the effect of propolis tablets on the occurrence and number of recurrent aphthous ulcers. The patients were blinded to the type of drug used. The control group received placebo while the test group received one $500 \mathrm{mg}$ capsule of propolis per day. Recurrence of aphthous ulcers was assessed every two weeks. The results showed a reduction in occurrence of aphthous ulcers in propolis group, which was statistically significant. Patients using propolis also gave a personal report regarding the recurrence of lesions, which revealed that propolis decreased the recurrence of ulcers and improved the quality of life of patients. Propolis forms a sticky protective layer on the wound, which prevents irritation of ulcer and also exerts anesthetic and anti-inflammatory effects. On the other hand, it seems that propolis stimulates the immune system and effectively decreases the recurrence of lesions.

\section{DISCUSSION}

Propolis has antimicrobial and anti-inflammatory properties. The caffeic acid and flavonoids present in the composition of propolis decrease the inflammatory response and by inhibiting the lipoxygenase and cyclooxygenase enzymes, prevent the conversion of arachidonic acid to prostaglandins and leukotrienes. Also, propolis enhances the function of the immune system since it induces the phagocytic activity and cell immunity. It helps in formation of hard tissue barrier since different enzymatic systems present in propolis participate in cell metabolism cycles and in collagen synthesis. These effects are attributed to the presence of vitamin B complex, pro-vitamin A, arginine and minerals such as copper, iron, zinc and bioflavonoids. These properties of propolis enhance wound healing (14). The internal environment of the hives must be free from microorganisms to allow growth of eggs laid by the queen bee. For her protection, the temperature of the hive must be maintained at $37^{\circ} \mathrm{C}$, and she must be away from light and moisture. This condition is close to the human body and propolis plays an important role in providing such conditions. Propolis is not used in its raw form. It should undergo purification and its aqueous or ethanolic extract must be obtained. Evidence shows that its alcoholic extract is more effective due to the release and better purification of flavonoids, which are the active component of propolis. Propolis is non-toxic and its safe dose is $1.4 \mathrm{mg} / \mathrm{kg}$ or $70 \mathrm{mg} /$ day for humans (40).

When applied on the skin, it usually does not cause any irritation. However, some people are allergic to propolis (41). The first report in this respect described allergy to propolis incorporated in cosmetics (42). The caffeic acid present in the composition of propolis causes allergy to propolis. Allergy to propolis is characterized by skin redness, rash, swelling, itch and skin cracks. Moreover, the skin may burn at the site of contact or develop psoriasis eczema. Oral lesions may also occur. It has been stated that people who are allergic to pollens are also allergic to propolis. Pollens in propolis might have been originated from any plant from areas not close to the place where propolis is purchased. Asthmatic patients should not use propolis because its chemical constituents or impurities may trigger asthmatic attack. Also, those allergic to bee sting must not use propolis since it may cause side effects similar to those of bee sting (13). Some studies evaluated the effect of Brazilian propolis on sneezing and coryza (allergic rhinitis in general) and showed that it was effective in decreasing the symptoms of allergic rhinitis via inhibiting the release of histamine. Two-week use of propolis with 1000 $\mathrm{mg} / \mathrm{kg}$ dose significantly decreased the symptoms of allergic rhinitis.

No study was found on the effects of propolis on pregnant women and fetus. Thus, our information is limited in this respect and pregnant, and nursing women would better not to use propolis. Propolis commercially used in cosmetics and supplements is often associated with ethanol. Such a high percentage of alcohol in propolis can cause vomiting if used along with disulfiram (Antabuse) or metronidazole flagyl. It has strong antibacterial activity, and a study showed that it had a synergistic effect with other antibiotics (37). Some other studies indicated the analgesic effects of propolis on skin wounds. Moreover, it has been shown that addition of propolis to toothpastes and

DOI: http://dx.doi.org/10.4314/ejhs.v28i4.16 
mouthwashes enhances their antimicrobial activity and decreases plaque accumulation at the margins and, therefore, would be effective for treatment of gingivitis.

Researchers conducted several cohort studies and clinical trials and indicated that propolis was suitable for use as mouthwash (13) and to decrease inflammation and dentin sensitivity (31) and for its antifungal effects. However, use of propolis in dentistry requires further and more comprehensive investigations (37). Also, it is noteworthy that the structure and composition of propolis may vary depending on its geographical origin and even the season of the year.

Considering the benefits of propolis and its confirmed anti-inflammatory, antibacterial and antifungal activity, and more importantly, stimulation of the immune system, it can be called a single agent that can be used for multiple purpose with zero to few side effect compared to those drugs used for the same diseases of oral health. However, further studies are warranted in this respect.

\section{REFERENCES}

1. Wander P. Taking the sting out of dentistry. Dental Practice. 1995; 25(1995):3-4.

2. Krol W, Czuba Z, Scheller S, Gabrys J, Grabiec S, Shani J. Anti-oxidant property of ethanolic extract of propolis (EEP) as evaluated by inhibiting the chemiluminescence oxidation of luminol. Biochemistry International. 1990;21(4):593-7.

3. Velazquez C, Navarro M, Acosta A, Angulo A, Dominguez Z, Robles R, et al. Antibacterial and free-radical scavenging activities of Sonoran propolis. Journal of Applied Microbiology. 2007; 103(5):1747-56.

4. Park YK, Alencar SM, Aguiar CL. Botanical origin and chemical composition of Brazilian propolis. Journal of Agricultural and Food Chemistry. 2002;50(9):2502-6.

5. Seidel V, Peyfoon E, Watson DG, Fearnley J. Comparative study of the antibacterial activity of propolis from different geographical and climatic zones. Phytotherapy Research. 2008;22(9):1256-63.
6. Orsi R, Sforcin J, Rall V, Funari S, Barbosa L, Fernandes J. Susceptibility profile of Salmonella against the antibacterial activity of propolis produced in two regions of Brazil. Journal of Venomous Animals and Toxins including Tropical Diseases. 2005; 11(2):10916.

7. Ikeno K, Ikeno T, Miyazawa C. Effects of propolis on dental caries in rats. Caries Research. 1991; 25(5):347-51.

8. Koru O, Toksoy F, Acikel CH, Tunca YM, Baysallar M, Guclu AU, et al. In vitro antimicrobial activity of propolis samples from different geographical origins against certain oral pathogens. Anaerobe. 2007;13(3):140-5.

9. Kujumgiev A, Tsvetkova I, Serkedjieva Y, Bankova V, Christov R, Popov S. Antibacterial, antifungal and antiviral activity of propolis of different geographic origin. Journal of ethnopharmacology. 1999; 64(3):235-40.

10. Borrelli F, Maffia P, Pinto L, Ianaro A, Russo A, Capasso F, et al. Phytochemical compounds involved in the anti-inflammatory effect of propolis extract. Fitoterapia. 2002; 73:S53-S63.

11. Poppe B, Michaelis H. Results of a twiceyearly controlled oral hygiene activity using a propolis-containing toothpaste (double-blind study). Stomatologie der DDR. 1986; 36(4):195-203.

12. Dodwad V, Kukreja BJ. Propolis mouthwash: A new beginning. Journal of Indian Society of Periodontology. 2011; 15(2):121.

13. Cowan M. Plant products as antimicrobial agents. Clin. Microbial. Rev., 22: 564-582. 1999.

14. Lotfy M. Biological activity of bee propolis in health and disease. Asian Pac J Cancer Prev. 2006;7(1):22-31.

15. Magro FILHO O, de CARVALHO ACP. Application of propolis to dental sockets and skin wounds. The Journal of Nihon University School of Dentistry. 1990;32(1):4-13.

16. Olczyk P, Wisowski G, Komosinska-Vassev $\mathrm{K}$, Stojko J, Klimek K, Olczyk M, et al. Propolis modifies collagen types I and III

DOI: http://dx.doi.org/10.4314/ejhs.v28i4.16 
accumulation in the matrix of burnt tissue. Evidence-Based Complementary and Alternative Medicine. 2013;2013.

17. Martin MP, Pileggi R. A quantitative analysis of Propolis: a promising new storage media following avulsion. Dental traumatology. 2004;20(2):85-9.

18. Özan F, Polat ZA, Er K, Özan Ü, Değer O. Effect of propolis on survival of periodontal ligament cells: new storage media for avulsed teeth. Journal of Endodontics. 2007;33(5):570-3.

19. Gopikrishna V, Baweja PS, Venkateshbabu N, Thomas T, Kandaswamy D. RETRACTED: Comparison of Coconut Water, Propolis, HBSS, and Milk on PDL Cell Survival. Journal of Endodontics. 2008;34(5):587-9.

20. Al-Shaher A, Wallace J, Agarwal S, Bretz W, Baugh D. Effect of propolis on human fibroblasts from the pulp and periodontal ligament. Journal of endodontics. 2004;30(5):359-61.

21. Al-Qathami H, Al-Madi E. Comparison of sodium hypochlorite, propolis and saline as root canal irrigants: A pilot study. Saudi Dent J. 2003;15(2):100-3.

22. Kandaswamy D, Venkateshbabu N, Gogulnath D, Kindo A. Dentinal tubule disinfection with $2 \%$ chlorhexidine gel, propolis, morinda citrifolia juice, $2 \%$ povidone iodine, and calcium hydroxide. International endodontic journal. 2010;43(5):419-23.

23. Oncag O, Cogulu D, Uzel A, Sorkun K. Efficacy of propolis as an intracanal medicament against Enterococcus faecalis. General dentistry. 2006;54(5):319-22.

24. Awawdeh L, AL-Beitawi M, Hammad M. Effectiveness of propolis and calcium hydroxide as a short-term intracanal medicament against Enterococcus faecalis: A laboratory study. Australian Endodontic Journal. 2009;35(2):52-8.

25. Rezende GPdSR, Costa LRdRS, Pimenta FC, Baroni DA. In vitro antimicrobial activity of endodontic pastes with propolis extracts and calcium hydroxide: a preliminary study. Brazilian dental journal. 2008;19(4):301-5.
26. Özan F, Sümer Z, Polat ZA, Er K, Özan Ü, Deger O. Effect of mouthrinse containing propolis on oral microorganisms and human gingival fibroblasts. European journal of dentistry. 2007;1(4):195.

27. Fearnley J. Bee propolis: natural healing from the hive: Souvenir; 2001.

28. Hayacibara MF, Koo H, Rosalen PL, Duarte $\mathrm{S}$, Franco EM, Bowen $\mathrm{WH}$, et al. In vitro and in vivo effects of isolated fractions of Brazilian propolis on caries development. Journal of Ethnopharmacology. $2005 ; 101(1): 110-5$.

29. Koo H, Rosalen PL, Cury JA, Park YK, Bowen WH. Effects of compounds found in propolis on Streptococcus mutans growth and on glucosyltransferase activity. Antimicrobial agents and chemotherapy. 2002;46(5):1302-9.

30. Mahmoud A, Almas K, Dahlan A. The effect of propolis on dentinal hypersensitivity and level of satisfaction among patients from a university hospital Riyadh, Saudi Arabia. Indian journal of dental research: official publication of Indian Society for Dental Research. 1999;10(4):130-7.

31. Murray M, Worthington H, Blinkhorn A. A study to investigate the effect of a propolis-containing mouthrinse on the inhibition of de novo plaque formation. Journal of Clinical Periodontology. 1997;24(11):796-8.

32. Koo H, Cury JA, Rosalen PL, Ambrosano GM, Ikegaki M, Park YK. Effect of a mouthrinse containing selected propolis on 3day dental plaque accumulation and polysaccharide formation. Caries Research. 2002;36(6):445-8.

33. Scheller S, Nolewajka E, Panasiewicz M, Dziekanowska D, Tustanowski J, Stojko A. Biological properties and clinical application of propolis. IV. The action of ethanol extract of propolis (EEP) on cells cultured in vitro. Arzneimittel-Forschung. 1977;27(8):1547.

34. Bassani-Silva S, Sforcin JM, Amaral AS, Gaspar LF, Rocha NS. Propolis effect in vitro on canine transmissible venereal tumor cells. Revista Portuguesa de Ciências Veterinárias. 2007;102(563/564):261-5.

DOI: http://dx.doi.org/10.4314/ejhs.v28i4.16 
35. Bufalo MC, Candeias JM, Sforcin JM. In vitro cytotoxic effect of Brazilian green propolis on human laryngeal epidermoid carcinoma (HEp2) cells. Evidence-Based Complementary and Alternative Medicine. 2009;6(4):483-7.

36. Sforcin J. Propolis and the immune system: a review. Journal of ethnopharmacology. 2007;113(1):1-14.

37. Sulaiman GM, Ad'hiah AH, Al-Sammarrae KW, Bagnati R, Frapolli R, Bello E, et al. Assessing the anti-tumour properties of Iraqi propolis in vitro and in vivo. Food and chemical toxicology. 2012;50(5):1632-41.

38. Chirumbolo S. Flavonoids in propolis acting on mast cell-mediated wound healing. Inflammopharmacology. 2012;20(2):99-101.
39. Viuda-Martos M, Ruiz-Navajas Y, Fernández-López J, Pérez-Álvarez J. Functional properties of honey, propolis, and royal jelly. Journal of food science. 2008;73(9).

40. Burdock G. Review of the biological properties and toxicity of bee propolis (propolis). Food and Chemical toxicology. 1998;36(4):347-63.

41. Walgrave SE, Warshaw EM, Glesne LA. Allergic contact dermatitis from propolis. Dermatitis. 2005;16(4):209-15. 